\title{
NICKEL IN COMPACTED GRAPHITE IRON
}

The paper presents results of the research work concerning effects of nickel concentration on the crystallization process, microstructure and selected properties of the compacted graphite iron. Compacted graphite in the cast iron was obtained with use of the Inmold process. The study has comprised the cast iron containing nickel up to concentration providing obtainment of austenitic microstructure of the matrix. The effect of the nickel on temperature of the eutectic crystallization was specified. It has been presented composition of the cast iron matrix in function of nickel concentration in a casting with wall thickness of $3 \mathrm{~mm}$ and $24 \mathrm{~mm}$. Moreover, it has been presented conditions defining the possibility of obtaining an austenitic and martensitic compacted graphite iron. Effect of the nickel on hardness of the cast iron was described.

Keywords: compacted graphite iron, crystallization process, DTA method

\section{Introduction}

In 2014, global volume of casting production of cast iron amounted approximately to 74.6 million tons, which accounted for $71 \%$ of its global production [1]. In Poland, it amounted approx. to $61 \%$. It demonstrates an enormous interest in this kind of material. The potential of the cast iron still seems to be not fully exploited. It is demonstrated by the number and the exceedingly wide range of studies concerning different types of the cast iron [2-8]. A special position among all kinds of the cast iron occupies a compacted graphite iron (CGI). In Poland, the compacted graphite iron is covered by the Standard PN-EN 16079: 2012. The standard specifies five grades of the CGI, providing the tensile strength from 300 to $500 \mathrm{MPa}$ at elongation from 2.0 to $0.5 \%$, respectively (Table 1 ). The microstructure of the cast iron matrix changes from a predominantly ferritic (grade EN-GJV-300) to fully pearlitic (grade EN-GJV-500). Compared to grey cast iron, the cast iron with vermicular graphite is characterized by higher strength and improved ductility. The microstructure of its matrix is less sensitive to wall thickness of the casting. Compared to cast iron with spheroidal graphite, the CGI offers the following advantages:

- lower coefficient of thermal expansion,

- higher heat conductivity,

- lower modulus of elasticity,

- $\quad$ lower thermally induced internal stress level,

- better thermoshock resistance and lower tendency to distortion because of the aforementioned properties,

- better damping capacity,

- $\quad$ better pouring properties (shrinkage, mould-filling, etc.).
TABLE 1

The grades of the CGI according to PN-EN 16079:2012

\begin{tabular}{|c|c|c|c|c|}
\hline \hline \multirow{2}{*}{ Grade } & \multicolumn{4}{|c|}{ Mechanical properties } \\
\cline { 2 - 5 } & $\begin{array}{c}\mathbf{R}_{\mathbf{m}}, \mathbf{M P a} \\
\mathbf{m i n} .\end{array}$ & $\begin{array}{c}\mathbf{R}_{\mathbf{p} \mathbf{0 . 2}} \text {, MPa } \\
\mathbf{m i n} .\end{array}$ & $\mathbf{A}, \mathbf{\%} \mathbf{m i n}$. & HBW \\
\hline EN-GJV-300 & 300 & 210 & 2.0 & $140-210$ \\
\hline EN-GJV-350 & 350 & 245 & 1.5 & $160-220$ \\
\hline EN-GJV-400 & 400 & 280 & 1.0 & $180-240$ \\
\hline EN-GJV-450 & 450 & 315 & 1.0 & $200-250$ \\
\hline EN-GJV-500 & 500 & 350 & 0.5 & $220-260$ \\
\hline
\end{tabular}

These advantages predestine this material for a variety of applications. The first utilitarian application of the compacted graphite iron was the brake discs for high speed railway rolling stock. At present, it is used mainly for construction of cylinder blocks of the internal combustion engines, exhaust manifolds, etc. Because of very interesting complex of properties offered by the CGI, it is the object of intensive research and numerous publications [9-12]. There is a fairly large group of publications describing the possibility of an ausferrite obtaining in the compacted graphite iron. This type of the cast iron is referred to as AVI or CAVI [13, 14]. However in the literature there are still not a lot of publications concerning the effect of alloying elements on the microstructure and properties of the CGI. Therefore, the aim of this study was to investigate the effect of the nickel on crystallization process, microstructure and selected properties of the compacted graphite iron.

\footnotetext{
LODZ UNIVERSITY OF TECHNOLOGY, DEPARTMENT OF MATERIALS ENGINEERING AND PRODUCTION SYSTEMS, STEFANOWSKIEGO 1/15, 90-924 ŁÓDŹ, POLAND

\# Corresponding author: grzegorz.gumienny@p.lodz.pl
} 


\section{Experimental (materials and methods)}

The cast iron was melted in an electric medium-frequency induction crucible furnace of $30 \mathrm{~kg}$ capacity. The charge to the furnace consisted of the special pig iron with a reduced concentration of sulfur (Table 2), ferrosilicon FeSi75, ferromanganese FeMn75, and the technically pure nickel. The chemical composition of the cast iron used for the tests is presented in Table 3. The sulfur concentration ranged between $0.01 \div 0.02 \%$, while phosphorus $-0.05 \div 0.07 \%$

TABLE 2

The chemical composition of the special pig iron

\begin{tabular}{|c|c|c|c|c|}
\hline \hline \multicolumn{5}{|c|}{ Chemical composition, wt\% } \\
\hline C & Si & Mn & P & S \\
\hline 3.91 & 0.22 & 0.05 & 0.07 & 0.02 \\
\hline
\end{tabular}

TABLE 3

Chemical composition of the CGI tested

\begin{tabular}{|c|c|c|c|c|}
\hline \multirow{2}{*}{ No. } & \multicolumn{4}{|c|}{ Chemical composition, wt\% } \\
\cline { 2 - 5 } & $\mathbf{C}$ & $\mathbf{S i}$ & $\mathbf{M n}$ & $\mathbf{N i}$ \\
\hline 1 & 3.53 & 2.38 & 0.27 & - \\
\hline 2 & 3.41 & 2.28 & 0.30 & 1.47 \\
\hline 3 & 3.53 & 2.11 & 0.30 & 3.10 \\
\hline 4 & 3.51 & 2.29 & 0.30 & 5.12 \\
\hline 5 & 3.35 & 2.24 & 0.29 & 9.26 \\
\hline 6 & 3.35 & 2.26 & 0.27 & 14.86 \\
\hline 7 & 3.28 & 2.21 & 0.28 & 16.53 \\
\hline 8 & 3.21 & 2.29 & 0.28 & 21.04 \\
\hline
\end{tabular}

The Inmold process was used of to obtain the compacted graphite. The schematic layout of elements in the mould is presented in Figure 1. Pouring temperature was approx. $1480^{\circ} \mathrm{C}$. The master alloy was placed in the spherical reaction chamber (2). The chemical composition of the master alloy is shown in Table 4. Behind the reaction chamber there was a mixing chamber (3). It allowed a proper mixing process of the master alloy and a liquid metal. Behind the mixing chamber there was a control chamber (4). In its thermal center, the PtRh10-Pt ther-

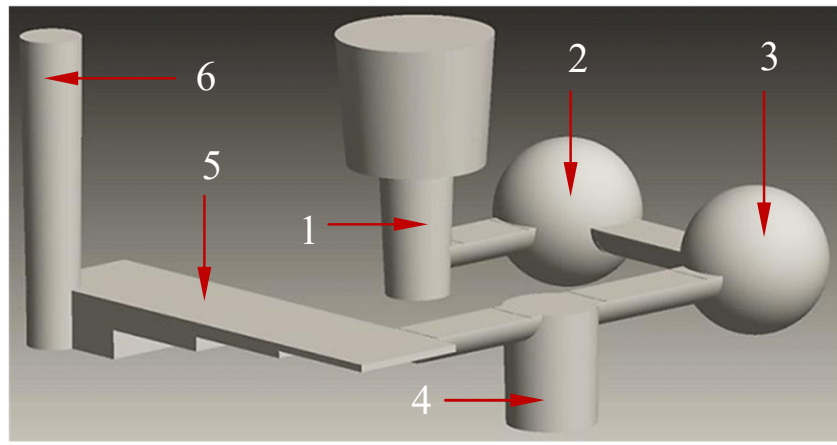

1 - downsprue, 2 - reaction chamber, 3 - mixing chamber, 4 - control chamber, 5 - test casting,

$$
6 \text { - flow -off }
$$

Fig. 1. Schematic layout of the elements in the mould mocouple was located to registration the crystallization process. As a next in the gating system, a stepped test casting with the wall thickness $3,6,12$ and $24 \mathrm{~mm}$ can be found.

TABLE 4

The chemical composition of the master alloy

\begin{tabular}{|c|c|c|c|c|c|}
\hline \hline \multicolumn{7}{|c|}{ Chemical composition, wt\% } \\
\hline $\mathbf{S i}$ & $\mathbf{M g}$ & $\mathbf{C a}$ & La & Al & Fe \\
\hline $44 \div 48$ & $5 \div 6$ & $0.4 \div 0.6$ & $0.25 \div 0.40$ & $0.8 \div 1.2$ & rest \\
\hline
\end{tabular}

The metallographic examinations were done with use of samples cut-off from the central part of the stepped casting. The Nikon Eclipse MA200 optical microscope and magnification $\times 500$ were used to the metallographic examinations. The surface fraction of the particular phases was examined by means of the NIS-Elements BR image analysis program. As an etchant $4 \%$ Mi1Fe was used. The hardness of the cast iron was examined on specimens cut-off from the casting with wall thickness of $24 \mathrm{~mm}$ with the HPO-2400 hardness tester using a test load of $1840 \mathrm{~N}$ and a ball of diameter $2.5 \mathrm{~mm}$. The microhardness was measured on specimens cut-off from the casting with wall thickness of $12 \mathrm{~mm}$ with the HV-1000B microhardness tester under load of $0.9807 \mathrm{~N}$ in accordance with the PN EN ISO 6507-1 standard.

\section{Results and discussion}

Figure 2 shows the exemplary DTA curves of the compacted graphite iron containing approx. 5\% Ni. The crystallization process started with precipitation of the austenite dendrites. The crystallization of the pre-eutectic phase is visible on the derivative curve as the $\mathrm{AB}$ thermal effect. The next thermal effect (DEF) comes from the crystallization of the austenite + vermicular graphite eutectic mixture. The crystallization process finished at $1126^{\circ} \mathrm{C}$ (H point, Fig. 2). With the change of nickel concentration, the number of thermal effects on the DTA curves has remained unchanged. What has changed was temperature of the phases crystallization. Therefore, Table 5 compares the temperature at the points describing DTA curves of cast iron with compacted graphite.

TABLE 5

Summary of the temperature at the points describing DTA curves of the CGI

\begin{tabular}{|c|c|c|c|c|c|c|}
\hline \multirow{2}{*}{$\begin{array}{c}\text { Ni concentration, } \\
\text { wt\% }\end{array}$} & \multicolumn{6}{|c|}{ Temperature at the characteristic points, ${ }^{\circ} \mathbf{C}$} \\
\cline { 2 - 7 } & $\mathbf{t A}$ & $\mathbf{t B}$ & $\mathbf{t D}$ & $\mathbf{t E}$ & $\mathbf{t F}$ & $\mathbf{t H}$ \\
\hline- & - & - & 1149 & 1150 & 1151 & 1107 \\
\hline 1.47 & 1196 & 1185 & 1153 & 1155 & 1159 & 1108 \\
\hline 3.10 & 1181 & 1173 & 1156 & 1157 & 1159 & 1116 \\
\hline 5.12 & 1171 & 1168 & 1164 & 1166 & 1168 & 1126 \\
\hline 7.59 & 1171 & 1169 & 1166 & 1167 & 1170 & 1127 \\
\hline 9.26 & 1200 & 1191 & 1171 & 1173 & 1176 & 1128 \\
\hline 14.86 & 1252 & 1222 & 1176 & 1179 & 1180 & 1138 \\
\hline 16.53 & 1241 & 1226 & 1190 & 1190 & 1190 & 1143 \\
\hline 21.04 & 1214 & 1206 & 1199 & 1200 & 1201 & 1160 \\
\hline
\end{tabular}




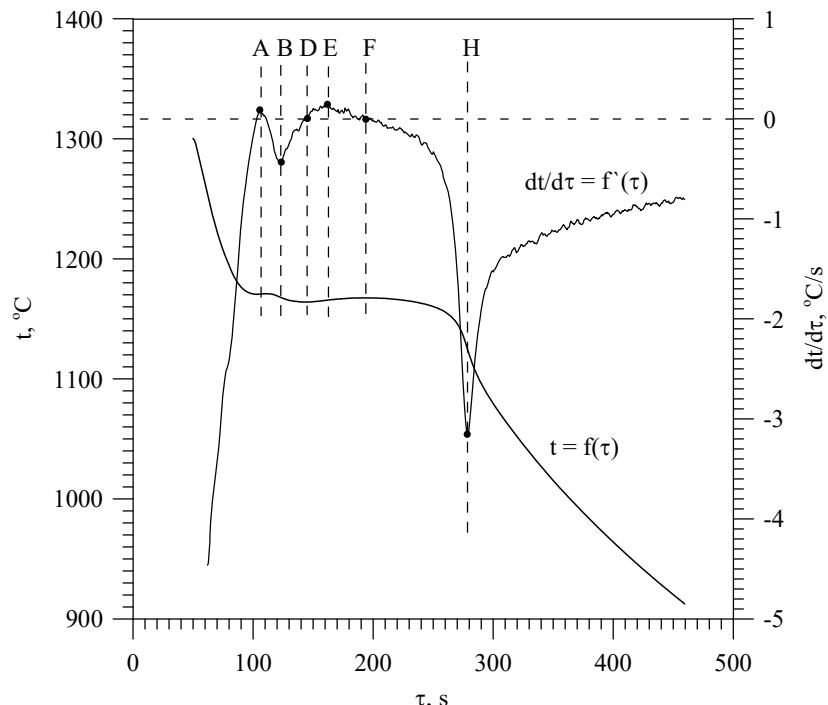

\begin{tabular}{|c|c|c|c|}
\hline Point & $\tau, \mathrm{s}$ & $\mathrm{t},{ }^{\circ} \mathrm{C}$ & $\mathrm{dt} / \mathrm{d} \tau$ \\
\hline A & 106 & 1171 & 0.09 \\
\hline B & 124 & 1168 & -0.43 \\
\hline D & 145 & 1164 & 0.00 \\
\hline E & 162 & 1166 & 0.14 \\
\hline F & 194 & 1168 & 0.00 \\
\hline H & 278 & 1126 & -3.15 \\
\hline
\end{tabular}

Fig. 2. DTA curves of the CGI containing $\sim 5 \% \mathrm{Ni}$

Data presented in the Table 5 show that the nickel increases the temperature of the eutectic crystallization, by increasing the tendency of the cast iron to crystallization according to the stable system (temperature at points $\mathrm{D}, \mathrm{F}$ and $\mathrm{H}$ ). The effect of the nickel on the eutectic transformation temperature is presented in Figure 3.

a)

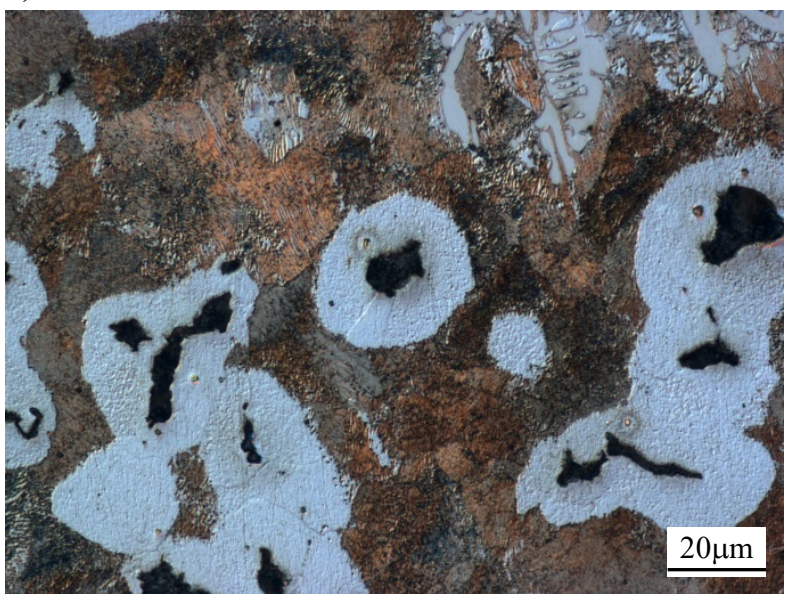

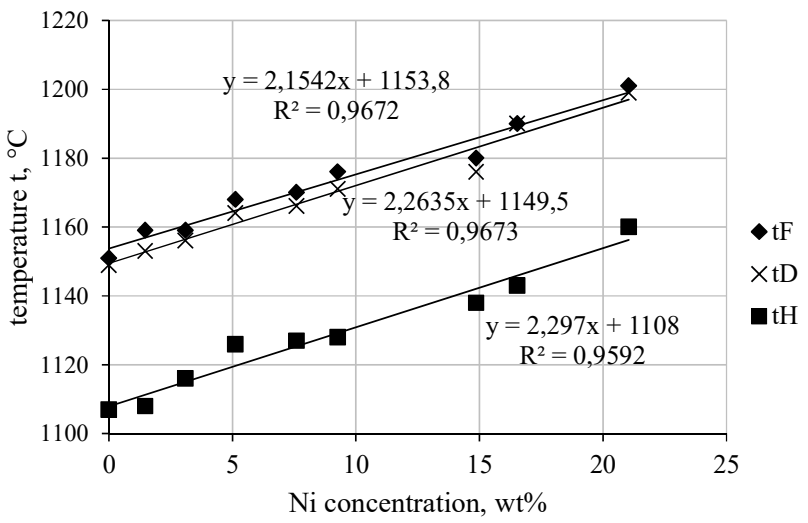

Fig. 3. The temperature of the eutectic transformation vs. nickel concentration

TABLE 6

Brinell hardness of the CGI

\begin{tabular}{|c|c|}
\hline \hline Ni concentration. wt\% & Brinell hardness \\
\hline- & 183 \\
\hline 1.47 & 215 \\
\hline 3.10 & 279 \\
\hline 5.12 & 435 \\
\hline 7.59 & 466 \\
\hline 9.26 & 451 \\
\hline 14.86 & 301 \\
\hline 16.53 & 227 \\
\hline 21.04 & 145 \\
\hline
\end{tabular}

From the data shown in Fig. 3 results that the nickel increases the eutectic transformation temperature by approx. $2^{\circ} \mathrm{C}$ per $1 \% \mathrm{Ni}$.

In Figure $4 \mathrm{a}, \mathrm{b}$ the microstructure of the unalloyed compacted graphite iron is presented.

b)

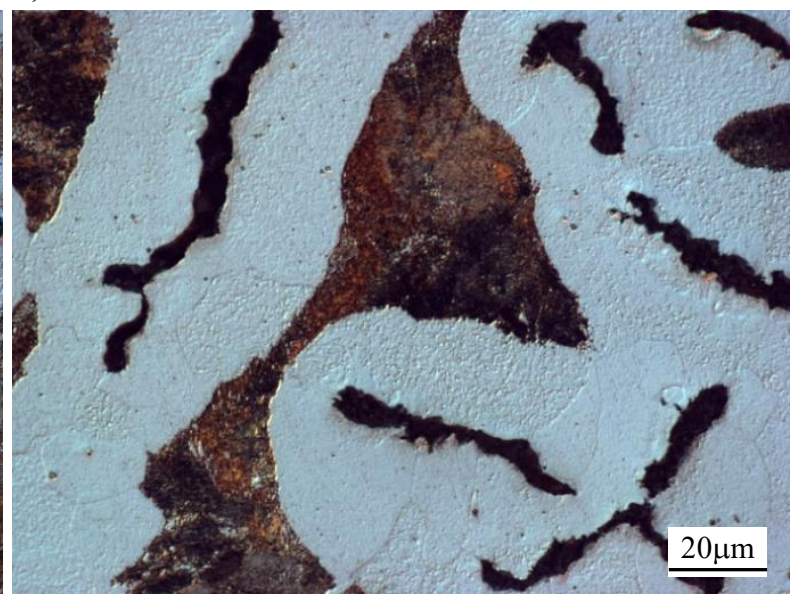

Fig. 4. The microstructure of unalloyed the CGI in castings with the wall thickness: a) $3 \mathrm{~mm}$, b) $24 \mathrm{~mm}$ : compacted graphite, pearlite, ferrite, cementite (only in $3 \mathrm{~mm}$ )

Data presented in Fig. 4a indicate that the matrix microstructure of the casting with wall thickness of $3 \mathrm{~mm}$ made of the unalloyed cast iron consists of pearlite $(\sim 66 \%)$, ferrite $(\sim 30 \%)$ as well as cementite separations in amount of approximately $4 \%$.
The increase in casting wall thickness resulted in the disappearance of the cementite precipitates and the increase in the amount of ferrite. In the casting with the wall thickness of $24 \mathrm{~mm}$, amount of ferrite was ca. $70 \%$ (Fig. 4b). 
Additive of approximately $1.5 \% \mathrm{Ni}$ to compacted graphite iron has resulted in a slight increase in amount of pearlite, while in castings with the wall thickness of $3 \mathrm{~mm}$ - the disappearance of the cementite. An exemplary microstructure of the CGI containing approximately $1.5 \% \mathrm{Ni}$ is shown in Figure 5.

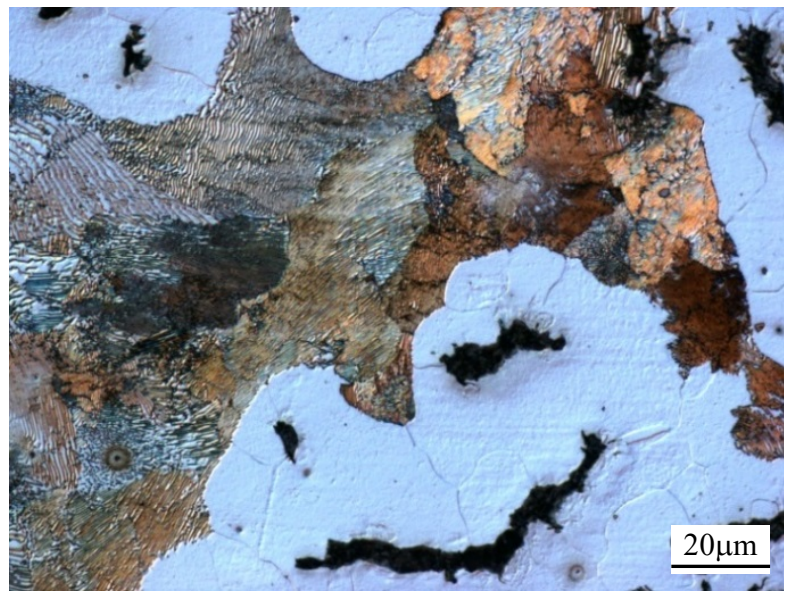

Fig. 5. The microstructure of the CGI containing $1.47 \% \mathrm{Ni}$ in castings with the wall thickness of $24 \mathrm{~mm}$ : compacted graphite, pearlite, ferrite
Increase in the nickel concentration to approximately $3 \%$ has caused a significant reduction in the amount of ferrite in the castings with the wall thickness of $3 \mathrm{~mm}(\sim 10 \%)$ as well as $24 \mathrm{~mm}(\sim 34 \%)$.

In the cast iron containing approximately $5 \% \mathrm{Ni}$ the matrix consists of martensite and a small amount of ferrite. The amount of ferrite increased with increasing the wall thickness of the casting. The microstructure of the cast iron containing approx. $5 \%$ of $\mathrm{Ni}$ is shown in Figure $6 \mathrm{a}, \mathrm{b}$.

Increase in the concentration to about $7.5 \%$ has resulted in the disappearance of ferrite and increased amount of the residual austenite. The microstructure of the martensitic compacted graphite iron in the casting with the wall thickness of 3 and $24 \mathrm{~mm}$ is shown in Figure 7a,b.

With increase in the nickel concentration the amount of austenite increased too, while its greater amount was observed in the thin-walled castings.

Fully austenitic matrix in the CGI was obtained at the nickel concentration of approximately $21 \%$ (Fig. 8). By using lower concentration of the $\mathrm{Ni}$, the martensite separations have occurred, as it is exemplified in Figure 9. a)

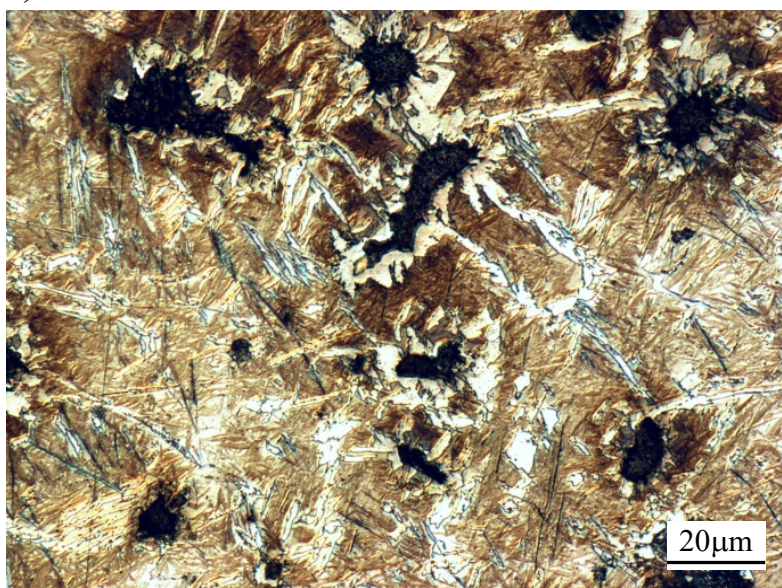

b)

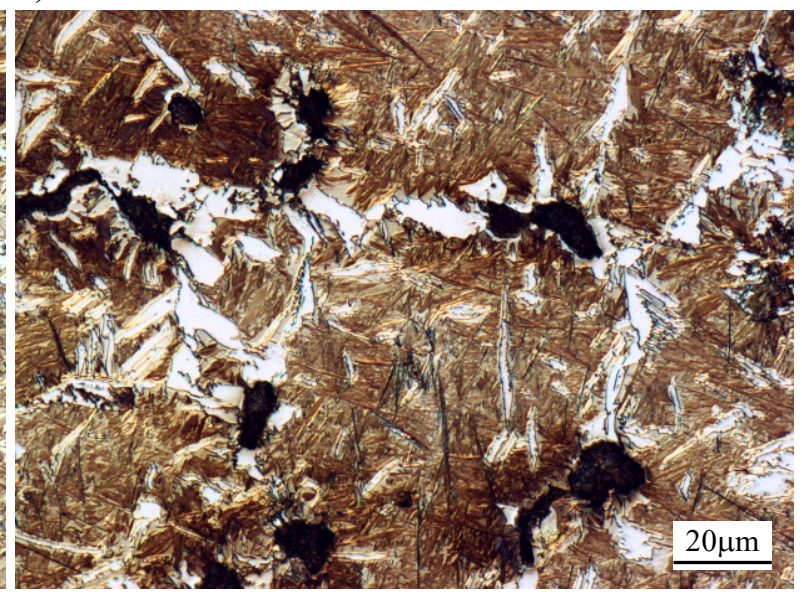

Fig. 6. The microstructure of the CGI containing 5.12\% Ni in castings with the wall thickness: a) $3 \mathrm{~mm}$, b) 24 mm: compacted graphite, martensite, ferrite, retained austenite

a)

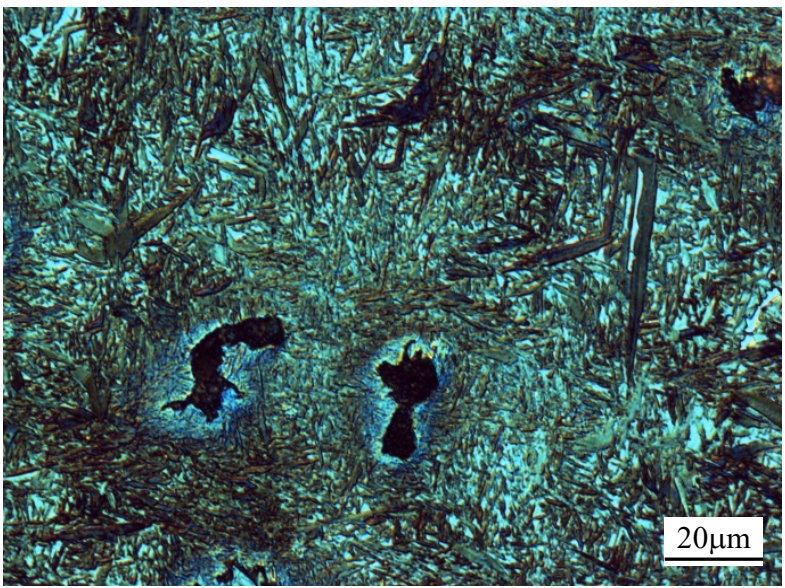

b)

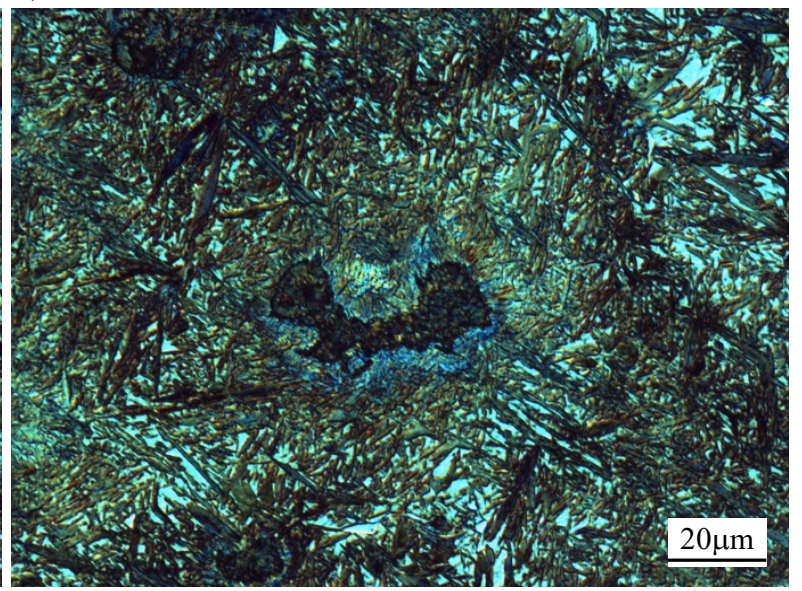

Fig. 7. The microstructure of the CGI containing $9.26 \% \mathrm{Ni}$ in castings with the wall thickness: a) $3 \mathrm{~mm}$, b) 24 mm: compacted graphite, martensite, retained austenite 


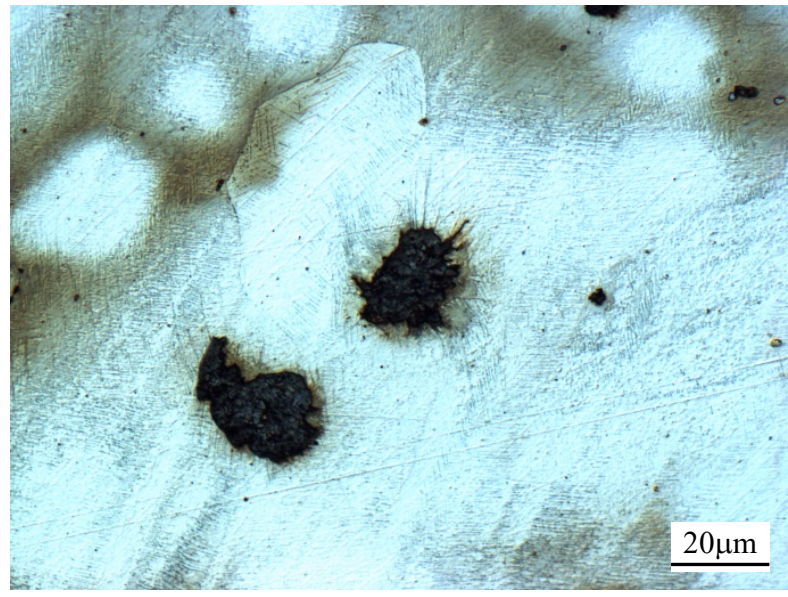

Fig. 8. The representative microstructure of the CGI containing $21.04 \%$ $\mathrm{Ni}$ in casting with the wall thickness of $24 \mathrm{~mm}$ : compacted graphite, austenite

In Figure $10 \mathrm{a}, \mathrm{b}$ the matrix of the compacted graphite iron vs. the nickel concentration in the casting with the wall thickness of 3 and $24 \mathrm{~mm}$ is presented.

From Fig. 10a results that the nickel at a concentration of up to approx. $3 \%$ is pearlite forming element. The increase in its concentration results in martensite precipitation, wherein

a)

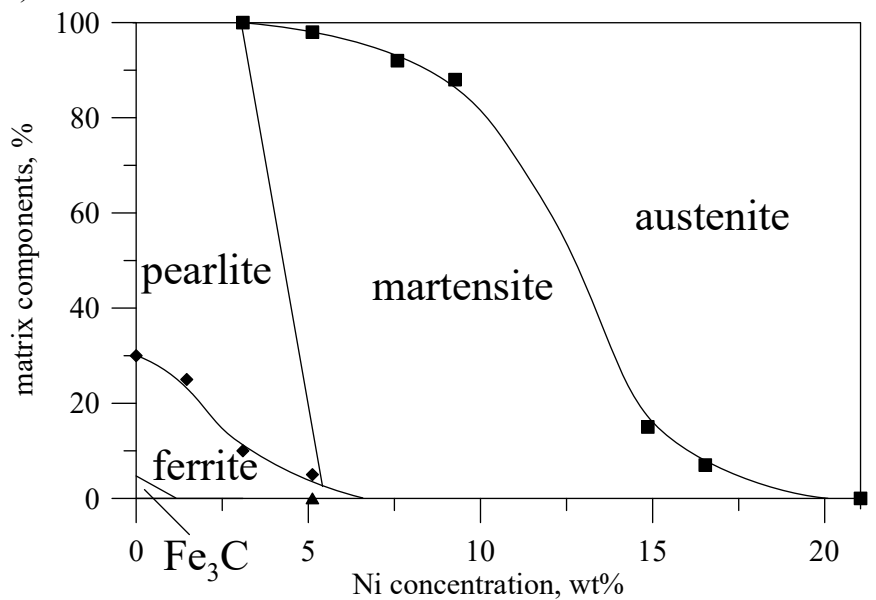

b)

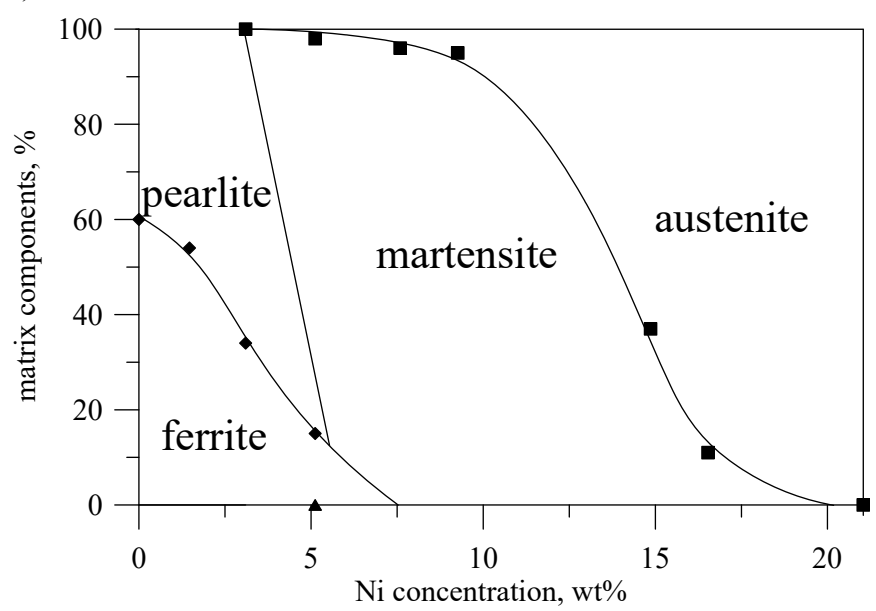

Fig. 10. Matrix composition of the CGI vs. nickel concentration in casting with the wall thickness: a) $3 \mathrm{~mm}$, b) $24 \mathrm{~mm}$

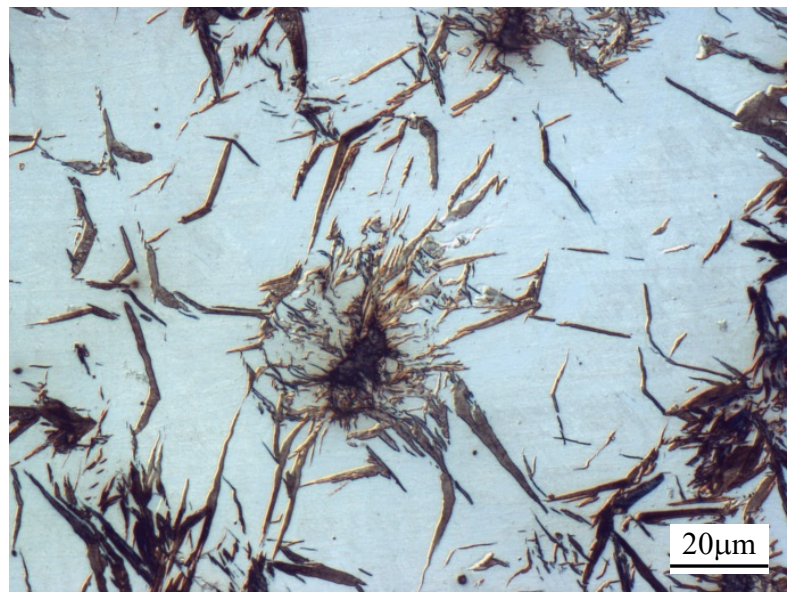

Fig. 9. The microstructure of the CGI containing $16.53 \% \mathrm{Ni}$ in castings with the wall thickness of $24 \mathrm{~mm}$ : compacted graphite, austenite, martensite

its amount is rapidly increasing in the range of $3-5 \% \mathrm{Ni}$. In the castings with the wall thickness of $24 \mathrm{~mm}$ made of the CGI containing $\sim 5 \% \mathrm{Ni}$ there is a higher amount of ferrite due to a lower heat transfer from the casting to the mould.

In Figure 11 hardness of the CGI vs. nickel concentration is presented.

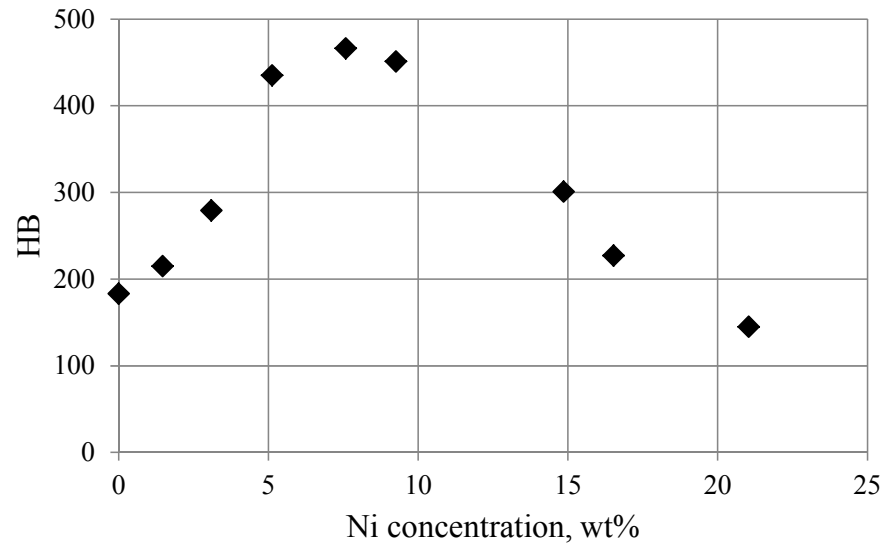

Fig. 11. The CGI hardness vs. nickel concentration

The CGI hardness increases to a concentration of about $3 \%$ nickel as a result of its pearlite-forming action. The nickel also slightly increased the microhardness of the pearlite from $214 \mu \mathrm{HV}$ for unalloyed cast iron to $226 \mu \mathrm{HV}$ for the cast iron containing approx. $3 \% \mathrm{Ni}$. Significant increase in the CGI hardness in the range of from 3 to approx. $5 \% \mathrm{Ni}$ takes place due to the presence of the martensite in the matrix. The highest hardness was obtained at concentration of approximately $7.5 \% \mathrm{Ni}$, when the matrix of the CGI was fully martensitic. The next decrease in the hardness is obviously due to increase in the amount of the austenite until absolute disappearance of the martensite at the concentration of approximately $21 \% \mathrm{Ni}$. 


\section{Conclusions}

From the data included in this paper the following conclusions can be drawn:

- the nickel increases temperature of the eutectic transformation by approx. $2^{\circ} \mathrm{C}$ per $1 \% \mathrm{Ni}$,

- $\quad$ in the CGI nickel is the pearlite forming element up to approximately $3 \%$,

- $\quad$ additive of approximately $7.5 \% \mathrm{Ni}$ results in obtaining martensitic compacted graphite iron in the castings with the wall thickness of $3 \div 24 \mathrm{~mm}$ cooled in the mould,

- an austenitic cast iron with compacted graphite is obtained with use of approx. $21 \% \mathrm{Ni}$,

- the maximum hardness of the CGI with the nickel (470 HB) was obtained at concentration of $7.5 \%$ nickel.

\section{REFERENCES}

[1] $49^{\text {th }}$ Census of World Casting Production. Mod. Cast., December 2015, 26-31.

[2] M. Soiński, A. Jakubus, Arch. Metall. Mater. 59 (3), 1073-1076 (2014).
[3] I. Olejarczyk-Wożeńska, H. Adrian, B. Mrzygłód, Arch. Metall. Mater. 59 (3), 981-986 (2014).

[4] M.F. Idham, B. Abdullah, A. Jaffar, M.H. Ibrahim, A. Ramli, Advanced Materials Research. 399-401, 172-175 (2012).

[5] C. Labrecque, M. Gagné, Canadian Metallurgical Quarterly 37 (5), 343-378 (1998).

[6] S. K. Putatunda, Materials Science and Engineering: A. 315 (1-2), 70-80 (2001).

[7] S. Kluska-Nawarecka, Z. Górny, D. Wilk-Kołodziejczyk, A. Smolarek-Grzyb, Arch. Metall. Mater. 52 (3), 375-380 (2007).

[8] S. Kluska-Nawarecka, D. Wilk-Kołodziejczyk, K. Regulski, G. Dobrowolski, Intelligent Information and Database Systems. 6592, 52-61 (2011).

[9] E. Guzik, Archives of Foundry Engineering. 10 (3), 95-100 (2010).

[10] E. Guzik, S. Dzik, Archives of Foundry Engineering. 9 (1), 175180 (2009).

[11] M. Górny, M. Kawalec, Archives of Foundry Engineering. 13 (2), 25-28. (2013).

[12] M. Górny, M. Kawalec, G. Sikora, Archives of Foundry Engineering. 14 (1), 139-142 (2014).

[13] A. Pytel, A. Gazda, Transactions of Foundry Research Institute. 54 (4), 23-31 (2014).

[14] M.S. Soiński, A. Jakubus, Arch. Metall. Mater. 59 (3), 1073-1076 (2014). 